\title{
How to construct and use a simple device to prevent the formation of precipitates when using Sudan Black B for histology
}

João Marcelo Santos de Oliveira ${ }^{1}$

Received: April 17, 2015. Accepted: July 1, 2015

\begin{abstract}
The present work aims to demonstrate the stages of fabrication and use of a simple device to avoid the formation or fixation of precipitates from Sudan Black B solution on tissues. The device consists of four coverslip fragments attached to a histology slide, which serve as points of support for the histological slide under analysis. To work properly, the histology slide with the sections should be placed with the sections facing downwards the device. A small space between the device and the histology slide is thereby created by the height of the coverslip fragments. When Sudan Black B is applied, the solution is maintained within the edges of the device and evaporation is minimized by the small space, thereby reducing the consequent formation of precipitates. Furthermore, by placing the sections facing downward the device, any sporadically formed precipitates are prevented from settling on and fixing to the sectioned tissues or organs. By avoiding the formation of precipitates, plant cells, tissues and organs can be better observed, diagnosed and photomicrographically recorded.
\end{abstract}

Keywords: histochemical tests, histology, lipids, plant anatomy, Sudan Black B

\section{Introduction}

Sudan reagents, including the traditional Sudan III, IV and Sudan Black B (SBB), are widely utilized to determine lipids (Horobin 2002) in animals, plants and hydrophobic materials, for a wide range of applications (Lillie 1977; Pfüller et al. 1977; O'Brien \& McCully 1981; Horobin 2002) and SBB is considered the most popular of the Sudan reagents (Bayliss 1981). Sudan III was first used for histochemical purposes at the end of the XIX century (Daddi 1896) and SBB use dates back to the 1930's (Lison \& Dagnelie 1935). The first mentions of histochemical uses in plants are in Kroemer (1903) for Sudan IV, in Guilliermond (1919) and Guilliermond (1921) for Sudan III and in Haasis (1944) for SBB.

SBB has been utilized to detect structural or reserve lipids in cells, tissues and diverse organisms, for example, in bacterial lipids (Hartman 1940; Burdon et al. 1947) and lipid granules found in leukocytes, the Golgi complex (Lillie 1977) and the nucleus (Fredericks 1977), as well as in elastin (Horobin \& James 1970) and bone (Ngoma \& Haumont 1974). SBB is also used to block the undesirable autofluorescence of lipids in immunological analyses (Romijn et al. 1999). In plants, it is used to detect cutinization and suberization of the cell wall (Ventrella et al. 2013) and reserve lipids (Bronner 1975; O’Brien \& McCully 1981; Ventrella et al. 2013; Oliveira 2015). Industrial uses of Sudan III, IV and Black B, as reported by Horobin (2002), include stain for organic solvents, printer ink, varnishes, resins, oils, fats, waxes, cosmetics and contact lenses.

Lansink (1968) isolated two pure fractions of Sudan Black $B$, in addition to impurities, and denominated them SBB-I and SBB-II. Subsequently, Pfüller et al. (1977) carried out a detailed investigation into the chemical structure of Sudan Black B in order to determine its histochemical properties and uses and found that SBB-I is lysochromic in neutral lipids, while SBB-II is a basic molecule that also reacts with nucleic acids and acidic mucopolysaccharides.

Because SBB-I makes up only $20 \%$ of the composition of commercial reagents and because it is lysochromic in neutral lipids (Lansink 1968; Pfüller et al. 1977), it is necessary to use concentrated or saturated solutions to detect lipids, as suggested by O'Brien \& McCully (1981). However, a saturated solution of Sudan, according to O'Brien \& McCully (1981), 'leads to the problem of messy sections due to stain precipitation if any evaporation occurs'. In order to minimize evaporation, and the consequent formation of precipitates, the use of a wet chamber and petri dish is recommended (O'Brien \& McCully 1981) and this method is widely utilized (Smart et al. 1986; Bevan et al. 1989; Bevilacqua et al. 1989; McGee \& Furby 1992; Knight et al. 2002). However, the wet chamber only reduces, but does not completely prevent, the formation of precipitates. Precipitates hinder the observation of a clean preparation and the interpretation of reserve lipids, which can be mistaken

${ }^{1}$ Laboratório de Botânica Estrutural. Depto. de Biologia. Universidade Federal de Santa Maria. Av. Roraima, 1000, 97105-900, Santa Maria, RS, Brazil. linneau@yahoo.com.br 
for precipitates, besides reducing the attractiveness of micrograph records for scientific publication.

The aim of this work is to present a method for constructing and using a simple device to prevent, or reduce to a minimum, the formation of precipitates during the application of saturated solutions with Sudan Black B reagent.

\section{Materials and methods}

\section{Botanical material}

Botanical samples consisted of anthers of Dyckia racinae L.B.Sm. and Dasyphyllum brasiliense (Spreng.) Cabrera and seeds of Ricinus communis $\mathrm{L}$. The anthers of D. racinae and of $D$. brasiliense were collected during anthesis, in the town of São Pedro do Sul, RS, Brazil. The vouchers of both species, were deposited in the SMDB Herbarium (n. 13840 and 12957, respectively). Seeds of $R$. communis were excised from ripe fruits of individuals found on the UFSM campus (Universidade Federal de Santa Maria, Santa Maria, Rio Grande do Sul, Brazil).

\section{Fixation, embedding and microtomy}

The samples were fixed in $1 \%$ glutaraldehyde and $4 \%$ formaldehyde (McDowell \& Trump 1976) in 0.1 M sodium phosphate buffer pH 7.2 (Gabriel 1982). Samples of Dyckia racinae anthers were dehydrated in an ethyl alcohol series and infiltrated in (2-hydroxyethyl)-methacrylate (HEMA) (O’Brien \& McCully 1981; Gerrits \& Smid 1983). Anthers of Dasyphyllum brasiliense and seeds of Ricinus communis were dehydrated and infiltrated using HEMA in order to preserve reserve lipids, since ethyl alcohol was not used for dehydration (Oliveira 2015) in the pollen grains and endosperm, respectively. Blocks of the three sample materials were sectioned with $5 \mu \mathrm{m}$ in thickness in a Leica RM2245 rotary microtome, equipped with a ' $D$ ' profile steel knife and with $1 \mu \mathrm{m}$ in a Thermo Scientific Finesse ME+ rotary microtome with a Thermo Scientific MB34 ${ }^{\circ}$ Dynasharp low-profile disposable blade. The sections were affixed on glass slides with a heating plate at a temperature of $60^{\circ} \mathrm{C}$ during 30 minutes.

\section{Microscopic analysis and photomicrographic record}

Photomicrographs were recorded and analyzed using a Leica DM2000 microscope, equipped with a Leica DFC295 digital camera, LAS software (Leica) and a Zeiss Axio Imager A2 microscope with AxioCam MCr digital camera and Zen software (Zeiss).

\section{Method for construction of Sudan reaction device}

Wash the histological slides and coverslip as recommended for glassware with detergent and rinse with distilled water. These materials often present large amounts of residues from packaging or oils from the technician's hands and this contamination hinders proper adhesion of the fragments to the slide, as described below.

Fragment a small coverslip, normally with dimensions of $20 \mathrm{X} 20 \mathrm{~mm}$ or $24 \mathrm{X} 24 \mathrm{~mm}$, utilizing protective eyewear. In order to create suitable fragments, place the coverslip on a flat and hard surface and position a retractable cutter blade with the cutting edge on the coverslip (Fig. 1A). Align the cutting blade on the coverslip in order to cut symmetrical portions of glass and press the blade down, cutting in a vertical direction (Fig. 1B-C). High-profile blades used for scraping or those with a metal back are recommended (Fig. 1A) to facilitate the operation. In addition, to prevent splattering of glass fragments when performing this procedure, place a drop of water at the center of a glass plate and position the coverslip on top of the drop, which will facilitate the cutting (Fig. 1D-E). Care must be taken when handling the glass fragments, as they may become firmly fastened to the surface on which they are cut. If this occurs, wait for the water to dry, or accelerate this process using filter paper.

Attach the coverslip fragments (Fig. 2A) by positioning two glass fragments at two corners of the slide and aligning two other fragments along the edge of the slide approximately three to four centimeters from the opposite edge (Fig. 2B). Apply a drop of adhesive to each of the four fixation points, and place the coverslip fragments on the drops of adhesive (Fig. 2B-D). Align the fragments with the edge of the histological slide. Verniz Vitral, Acrilex ${ }^{\mathrm{TM}}$, a synthetic colorless polyester resin varnish, was used for adhesion in this work.

Wait for the adhesive to dry and remove excess adhesive with a blade. The device is then ready for use (Figs. 2D, 3A).

\section{Sudan Black B solution}

The working solution is a saturated solution of Sudan Black B in 70\% ethyl alcohol made beforehand, as described by O’Brien \& McCully (1981).

\section{Method for proper use of the device}

This section describes the use of the device for histochemical tests with Sudan black B. A few sections should be affixed to the center of the histological slide (Fig. 3A-B) so that the target tissues do not come close to the edge of the device, where precipitates may form. For the present work, histology slides were made with two sections in each slide and then stained with $5 \%$ aqueous safranin in order to facilitate visualization of the sections (Fig. 3A-C).

It is important to remember that the slide should be placed with the sections facing downward the device, always maintaining this position with the histology slide on the device (Fig. 3A-B). The slide with the sections should be positioned asymmetrically on the support (Fig. 3A-C), in order to allow space to apply the reagent (Fig. 3B-C). With the aid of a pipette, apply the Sudan solution fully filling the space between the slide and the device (Fig. 3B-C). 

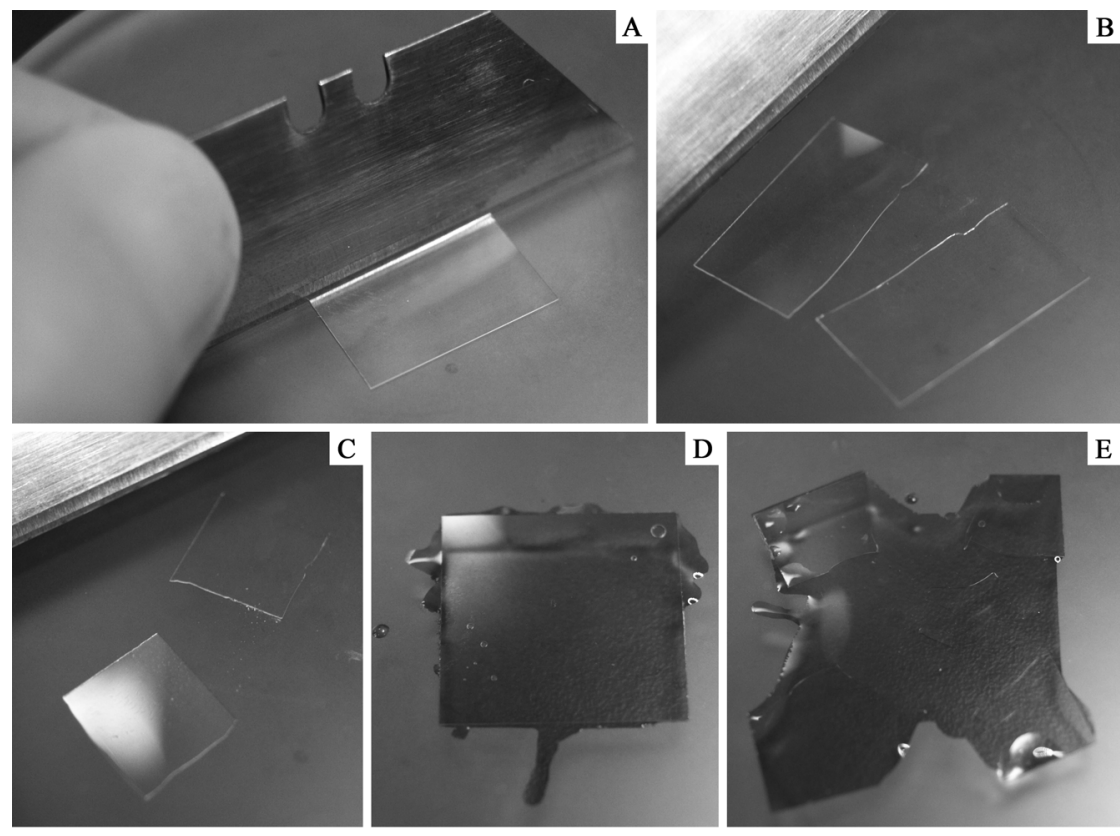

Figure 1. Initial step in the construction of the device to aid in reactions with Sudan Black B for lipid detection without formation of precipitates on histological cuts. A) Detail of 20X20mm slide and cutting tool to produce the glass fragments. B) First fragments. C) Aspect of final fragments, approximately square-shaped. D) Placement of slide on drop of water to aid in cutting the glass and avoid splattering of fragments. E) Completed fragments still in the presence of water.
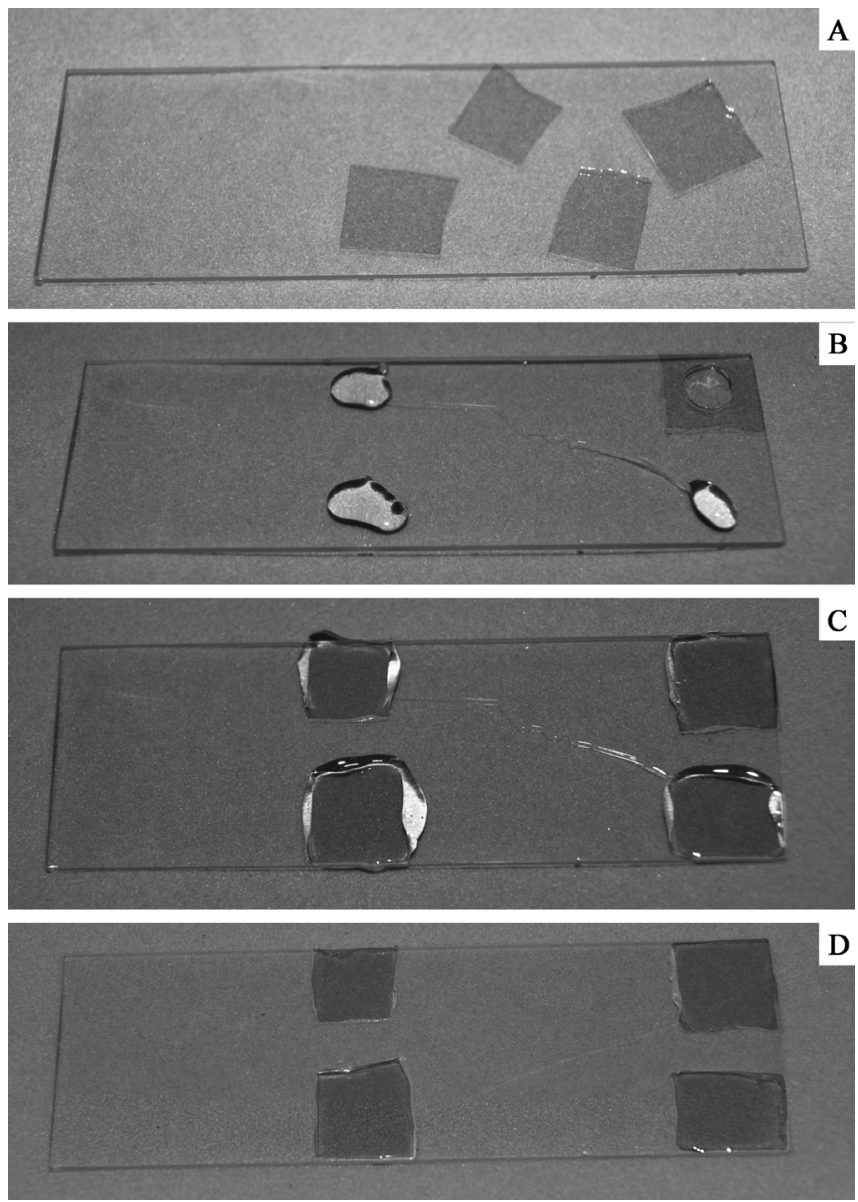

Figure 2. Construction steps of device to aid in reactions with Sudan Black B for lipid detection without formation of precipitates on histological cuts. A) Final fragments of slide on the histology slide. B) Use of adhesive made of polyester resin and adhesion of the first fragment of glass. Position of adhesive drops determines the position of fragments in the mechanism. C) Fragments fastened to the slide with excess of adhesive. D) Excess of resins removed with a razor blade. Device is ready for use. 

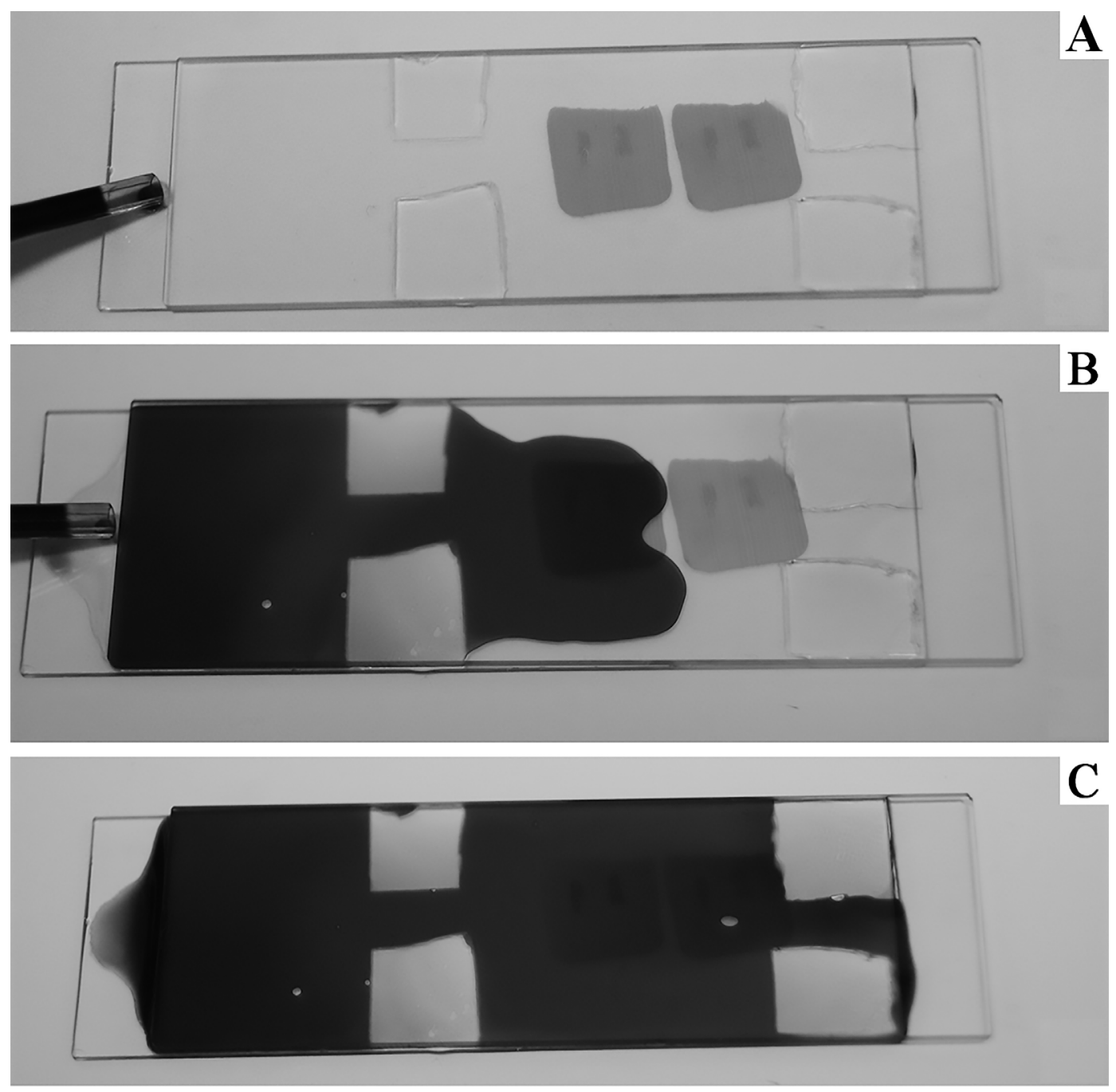

Figure 3. Steps of usage for the device to aid in reactions with Sudan Black B for lipid detection without formation of precipitates on histological cuts. A) Histological slide on the mechanism ready for use, with two cuts fixed and facing downwards. Note the position of the pipette on the device to apply the solution into the space between the device and the histological slide. B) Detail of the application process in which the solution entirely fills the space between device and slide. C) Space between device and slide fully filled with Sudan Black B solution.

\section{Interruption of the reaction}

After the reaction period, the process can be interrupted in two ways. The first consists of washing the slide with $70 \%$ ethyl alcohol using a pipette. It is important to guide the drainage by using a strip of filter paper at the opposite edge on which Sudan was applied (Fig. 4A) while slightly tilting the support (Fig. 4A-B). Usually, two applications of ethyl alcohol using plastic Pasteur pipettes with a volume of $3 \mathrm{ml}$ are sufficient. It is recommended that the device be placed in a petri dish before beginning the procedure to facilitate manipulation and inclination, thus avoiding direct manipulation (Fig. 4A-B). It is important to only slightly tilt the slides so that the alcohol used for washing can also accumulate between the histology slide and the device, while slowly draining. The second way to interrupt the reaction consists of immerging the slides and device in a flask with ethyl alcohol at the same concentration recommended for the procedure (Fig. 4C-D).

In both procedures it is essential to be careful with the sections during the separation of the histology slide from the device, because alcohol in the Sudan solution may cause sections to swell and detach (Rosenberg et al. 1960; O’Brien \& McCully 1981).

A part of the botanical material was used as a control and submitted to the reaction with Sudan Black B in a wet chamber as described by O'Brien \& McCully (1981). The solution with Sudan on the histology sections was removed with the aid of a paper towel, followed by washes with ethyl alcohol.

After washing, the usual procedures for mounting and observation of slides should be followed. Mounting is normally performed with glycerinated gelatin (O'Brien \& McCully 1981), water or glycerin (Ventrella et al. 2013) or a solution of glycerin in water at a proportion of 1:1. 

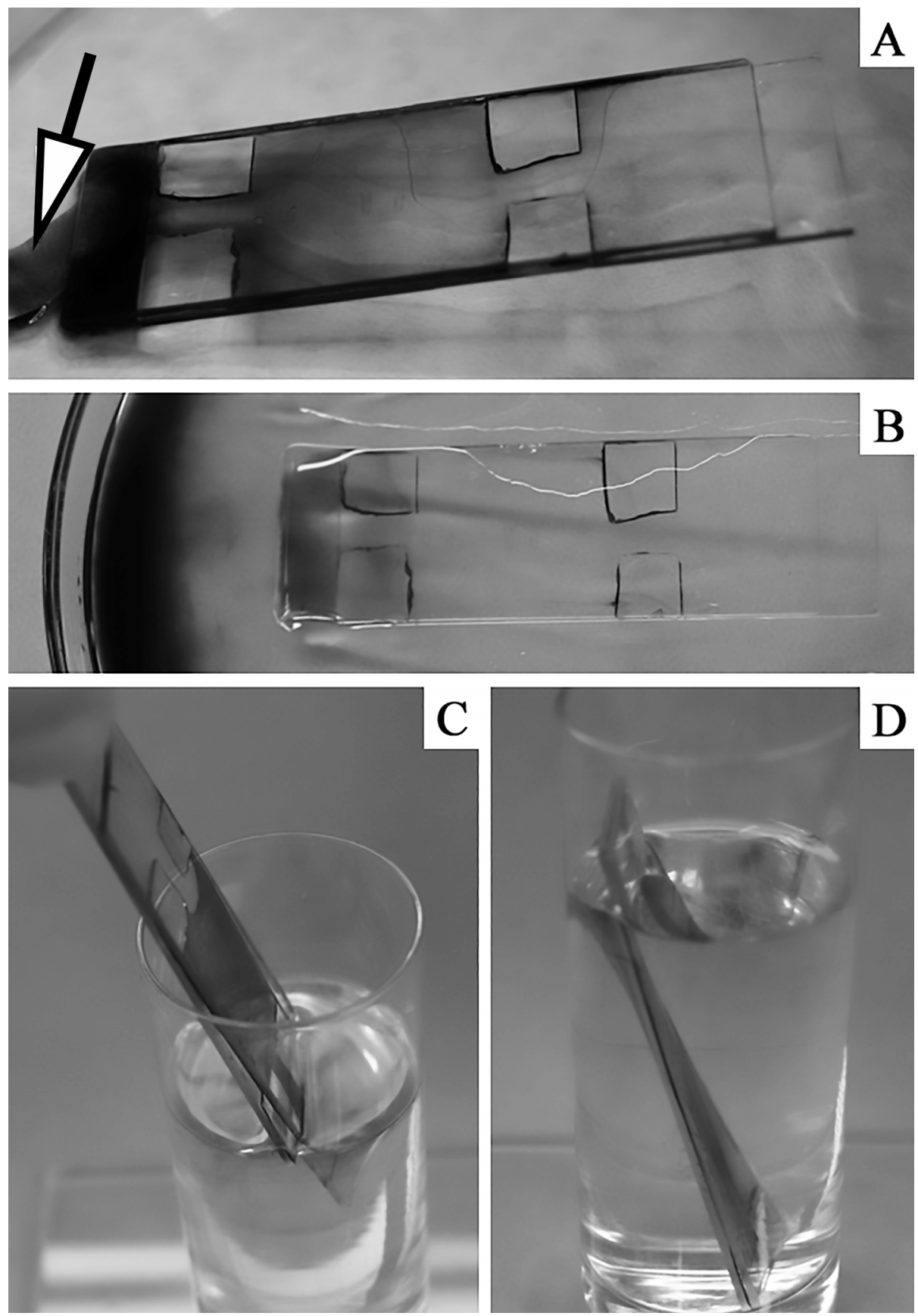

Figure 4. Details of the removal of Sudan Black B solution from the mechanism. A-B) Removal of Sudan Black B with application of 70\% ethyl alcohol between the device and slide with the slide and device held in a slightly inclined position. Arrow indicates the location where filter paper should be inserted to aid in the draining of the solution. C-D) Steps of solution removal with immersion of the slide and device in a flask with ethyl alcohol.

\section{Results}

Sections undergoing the usual procedure for reaction with Sudan Black B with a wet chamber generally present the accumulation of precipitates, which can generate problems for observation (Fig. 5A-D) and interpretation, mainly of the occurrence of reserve lipids, which can be mistaken for precipitates, besides making it difficult to record photomicrographs of large areas of tissue free of precipitates (Fig.
$5 \mathrm{~A}-\mathrm{B})$. Upon analyzing the images for general aspects of the Dyckia racinae anthers, it is possible to observe precipitate material on the slides undergoing reaction in a wet chamber (Fig. 5A), and this precipitate material is not formed on the slides that underwent reaction with Sudan using the proposed device (Fig. 6A-D). It was possible to observe the affect of Sudan Black B after 30 minutes of reaction, through the determination of structural lipids present in the cell walls and cuticle (Figs. 5A-B, 6A-B), exine (Figs. 5B-C, 6B-C) and 

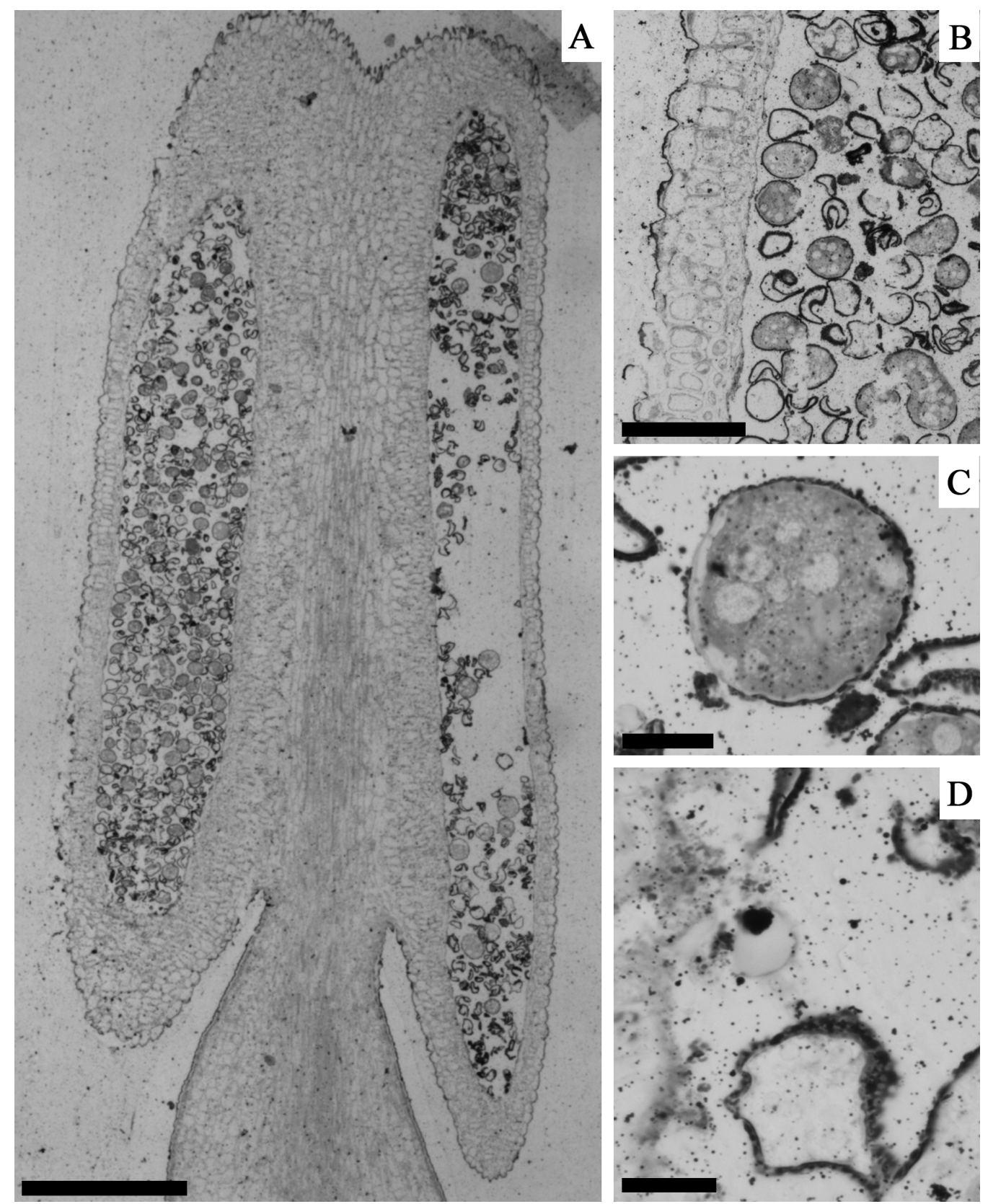

Figure 5. Light microscopy of longitudinal sections of Dyckia racinae anthers after undergoing reaction with Sudan Black B in a wet chamber according to O'Brien and McCully (1981). A) General aspect of the mature anther, including terminal part of the filament. Barr $=391 \mu \mathrm{m}$. B) Detail of the locule and sporangium filled with pollen grains. Barr $=96 \mu \mathrm{m}$. C) Detail of the pollen grain with exine strongly reactive to Sudan Black B. Precipitates make the diagnosis of lipids in the pollen grain and locular fluid difficult. Barr $=17.5 \mu \mathrm{m}$. D) Detail of the sporangium portion with tapetal cell debris. Precipitates make the correct identification of lipids difficult. Barr $=17.5 \mu \mathrm{m}$.

tapetal cell debris (Figs. 5D, 6D). The same was observed after five minutes of reaction in the anthers of Dasyphyllum brasiliense, allowing the detection of structural lipids in the epidermis and reserve lipids in pollen grains in addition to pollenkitt in the locule and on pollen grains (Fig. 7A) and reserve lipids in cotyledon cells of Ricinus communis seeds (Fig. 7B). However, the quality for analysis and photomicrographic record is higher in the slides undergoing Sudan reaction using the proposed device (Figs. 6A-D, 7A-B). The precipitates can be mistaken for reserve lipids, accumulated in drops (Fig. 5C), or cellular remains of a lipid nature (Fig. $5 \mathrm{D}$ ), while there is no difficulty diagnosing the occurrence of structural lipids in the tapetal cell debris in the locular fluid (Fig. 6A, C-D) or their absence in the pollen grains due to their removal after dehydration of anthers in ethyl alcohol (Fig. 6C). There is also no difficulty verifying the presence of preserved reserve lipids in pollen grains and in the cotyledon (Fig. 7A-B). 

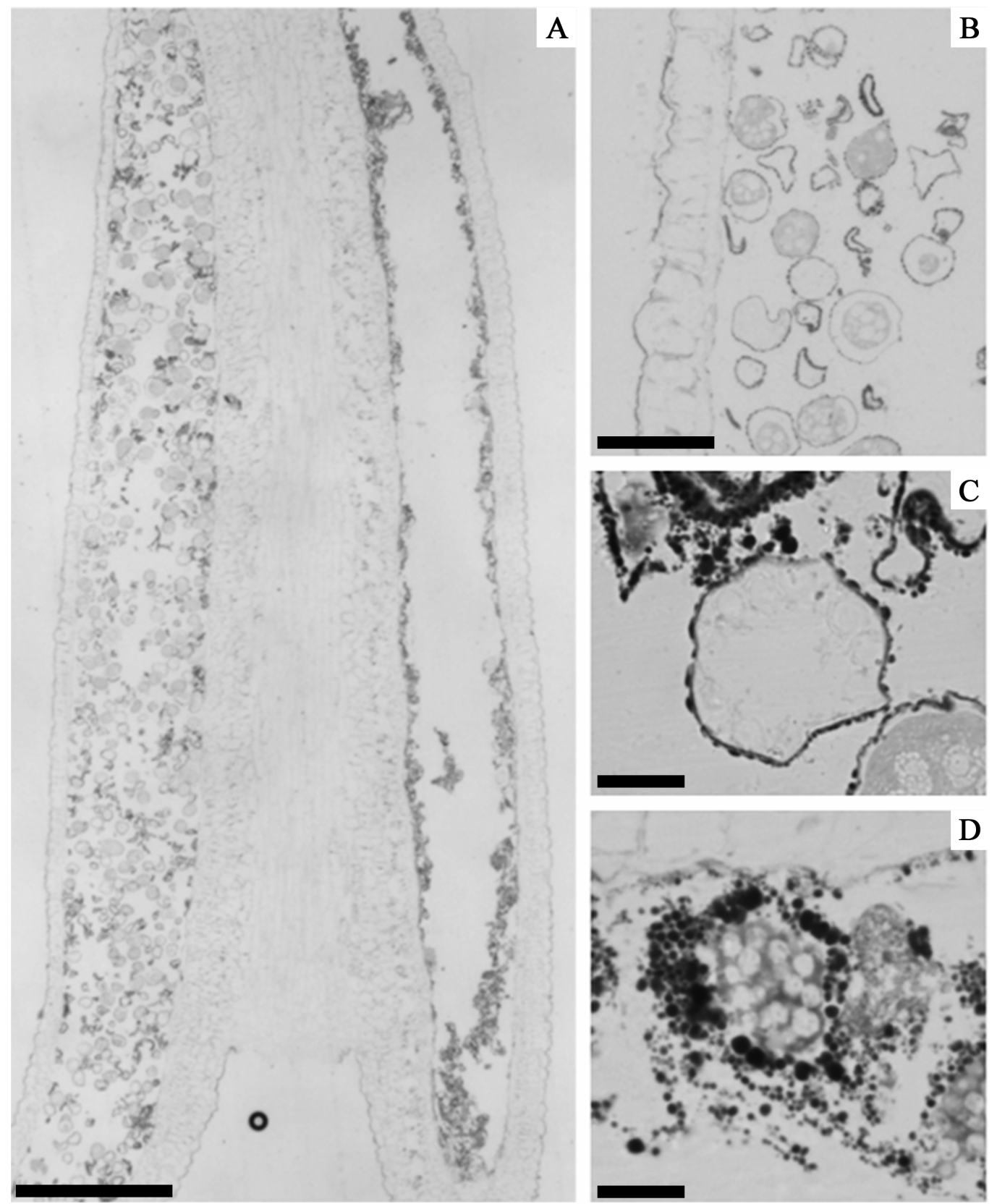

Figure 6. Light microscopy of longitudinal sections of Dyckia racinae anthers after undergoing reaction with Sudan Black B with the proposed device. A) General aspect of the mature anther, including terminal part of the filament. Barr $=391 \mu \mathrm{m}$. B) Detail of the locule and sporangium filled with pollen grains. Barr $=96 \mu \mathrm{m}$. C) Detail of the pollen grain with exine strongly reactive to Sudan Black B. Proposed procedure results in histology slide free of precipitates, allowing for the adequate diagnosis of structural and reserve lipids according to the histological method used for infiltration of anthers. Barr $=17.5 \mu \mathrm{m}$. D) Detail of the sporangium portion with tapetal cell debris. Absence of precipitates allows a precise characterization of sporangium and locular fluid in relation of the presence of lipids. Barr $=17.5 \mu \mathrm{m}$.

\section{Discussion}

The results demonstrate conclusively that the device tested and described produces histological preparations without precipitates of Sudan Black B, allowing for an improved photomicrographic record and analysis of cells, tissues and organs. The aim of our discussion is therefore not to present new results related to the location of lipids in cells or tissues in the species utilized, but rather to demonstrate the advantages of utilizing the proposed device for reaction of histological sections with Sudan Black B.

The material utilized for constructing the device are common to histological laboratories. The adhesive is generally sold as a colorless varnish and can easily be found in stores that sell school, art or hardware supplies.

Prior filtering and/or centrifugation of Sudan Black B minimizes the accumulation of precipitates on sections, but does not prevent the formation of new precipitates 

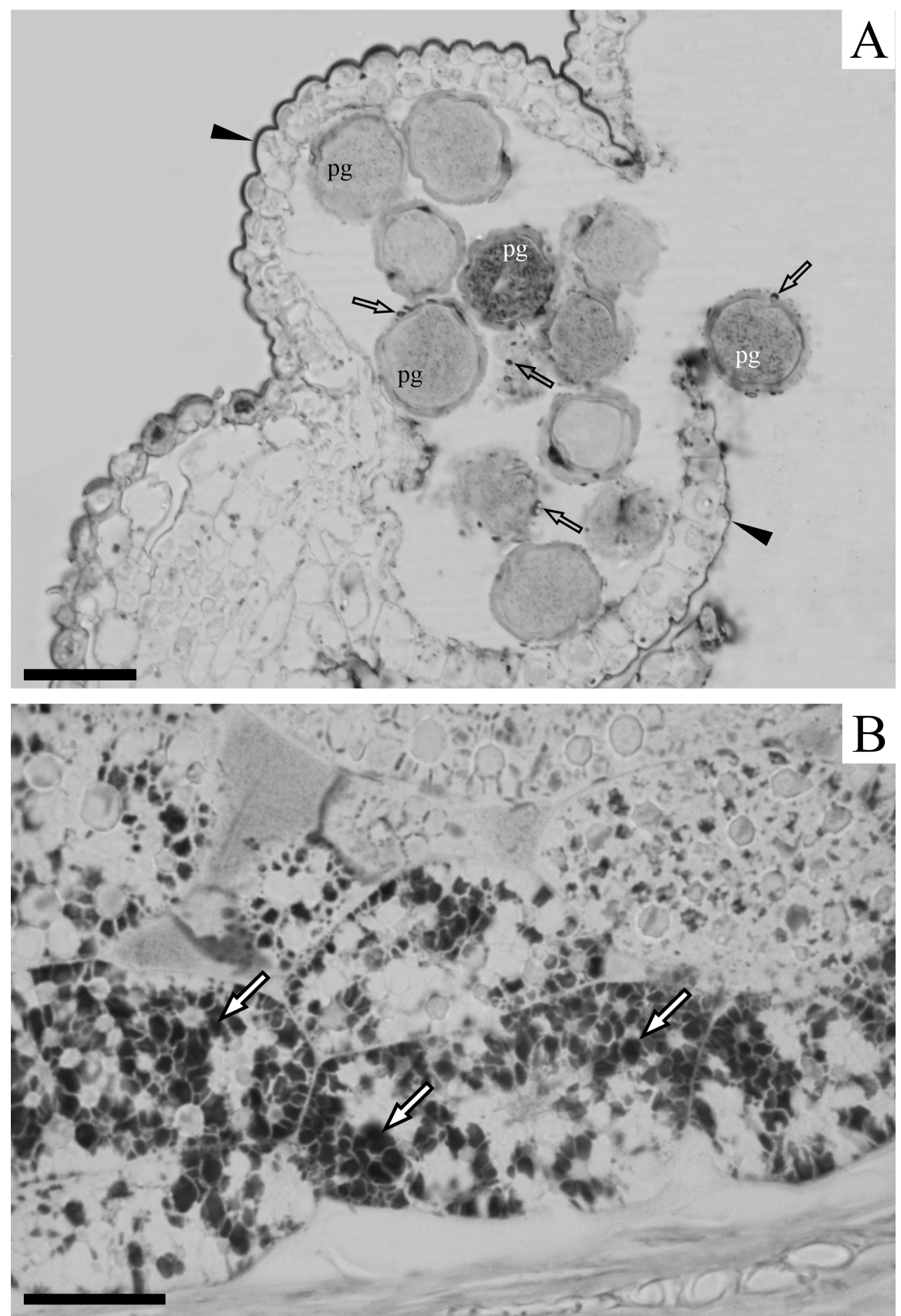

Figure 7. Light microscopy. A) Transversal section of anther of Dasyphyllum brasiliense after undergoing reaction with Sudan Black B with the aid of the proposed device. Pollen grains (pg) are full of lipid drops (small black dots). Arrowheads indicate cutinized portions of the epidermis. Unfilled arrows indicate pollenkitt. Barr $=33 \mu \mathrm{m}$. B) Transversal section of cotyledon of Ricinus communis after reaction with Sudan Black B. Arrows indicate lipid drops. Barr $=20 \mu \mathrm{m}$.

during the evaporation of alcohol, the typical solvent. These preventive procedures thus produce a smaller effect than the proposed device, which functions simultaneously to the reaction, impeding or minimizing the formation and accumulation of Sudan B precipitates.

With the use of the wet chamber, it was observed that precipitates are formed during the evaporation of alcohol mainly at the edges of the solution, on the slide and surface of the solution. A paper towel or filter paper can be efficiently used to remove surface precipitates, although this may lead to occasional mechanical damage to the sections. However, a certain amount of precipitates is retained and or spread over the sections in addition to that which is generated at the juncture between the solution and the slide. Decantation of precipitates on sections may also occur during the reaction, mainly those presenting longer times. The use of the proposed device significantly reduces the area for evaporation of the reagent and consequent formation of precipitates, since precipitates form on the periphery rather than directly on the sections. 
Assembly of the wet chamber, as described by O'Brien \& McCully (1981), must be repeated whenever the use of Sudan Black B is required, as opposed to the proposed device, which can be incorporated into the lab's glassware once it has been constructed. In addition, several devices can be constructed for simultaneous use and diverse reactions and/or users. The time that sections remain in the reagent can also be problematic when using the wet chamber. Depending on the reaction time, the alcohol may generate swelling, degradation and detachment of the acrylic resin (Rosenberg et al. 1960), leading to full or partial detachment of the sections (O'Brien \& McCully 1981) distortions, folds or losses of parts of the tissues. The detachment of sections is a common problem in the procedure and it can be exacerbated by the method used to remove the reagent. The use of the proposed device does not alter the action of alcohol on the resin, but it results in a more unproblematic removal of the reagent, besides preventing occasional damage to the sections caused by the paper towel or filter paper.

The method of dehydration in HEMA used in the present study for preserving lipids (Oliveira 2015), led to Sudan Black $B$ reaction times between 1 and 5 minutes with satisfactory results. This reduction in reaction time decreases the degradation of sections by alcohol. In addition, according to some authors, ethyl alcohol removes fatty acids from cells (Bayliss \& Adams 1972), and this process is intensified by longer reaction times. It is thus recommended that the proposed device be used in combination with the lipid preservation technique described by Oliveira (2015) for the Sudan Black B reaction, especially for tissues presumed to present cells with reserve lipids, typical in diaspores. Through this combination of techniques, the reduced reaction times and almost full absence of resin deformations allowed the re-use of the same slide for more than one reaction.

According to O'Brien \& McCully (1981), the precipitates typically formed with the use of Sudan Black B are generated because of evaporation of the solvent in the Sudan solution. The correct use of the proposed device greatly minimizes the area of solution evaporation and evaporation does not occur directly over the sections, avoiding or drastically reducing the formation of precipitates on the sections. In addition, the inverted position of the histology slide over the device hinders decantation and fixation of potential precipitates on the sections. With the alcohol washes, the Sudan solution and possible precipitates formed during the reaction or present in the solution are easily removed, as their fixation on the sections is significantly hindered. Thus, a more precise analysis and identification of structural or reserve lipid is possible, as well as a higher quality of photomicrographic record at different increases in magnitude. Additional advantages include the disposal of a wet chamber, reduction of additional precautions for precipitates existent in the solution and, thus, a simplification of the process, besides allowing for the possibility of carrying out more than one reaction on the same slide.

\section{References}

Bayliss HOB. 1981. The histochemical versatility of Sudan Black B. Acta Histochemica S 24: 247-255.

Bayliss HOB, Adams CWM. 1972. Bromine-Sudan Black: a general stain for lipids including free cholesterol. Histochemistry Journal 4: 505-515.

Bevan M, Shufflebottom D, Edwards K, Jefferson R, Schuch W. 1989. Tissue-and cell-specific activity of a phenylalanine ammonia-lyase promoter in transgenic plants. The EMBO Journal 8: 1899-1906.

Bevilacqua LR, Roti-Michelozzi G, Modenesi P. 1989. The watertight dormancy of Melilotus alba seeds: further observations on the palisade cell wall. Canadian Journal of Botany 67: 3453-3456.

Bronner R. 1975. Simultaneous demonstration of lipids and starch in plant tissues. Biotechnic \& Histochemistry 50: 1-4.

Burdon KL, Stokes JC, Kimbrough CE. 1947. Studies of the common aerobic spore-forming bacilli. I. Staining for fat with Sudan Black B safranin. Journal of Bacteriology 42: 717-724.

Daddi, L. 1896. Nouvelle méthode pour colorer la graisse dans les tissus. Archives Italiennes de Biologie 26: 143-146.

Frederiks WM. 1977. Some aspects of the value of Sudan Black B in lipid histochemistry. Histochemistry 54: 27-37.

Gabriel BL. 1982. Biological Electron Microscopy. 1st edn. New York, Van Nostrand Reinhold Company.

Gerrits PO, Smid L. 1983. A new less toxic polymerization system for the embedding of soft tissue in glycol methacrylate and subsequent preparing of serial sections. Journal of Microscopy 132: 81-85.

Guilliermond A. 1919. Obseration vitales sur le chondriome des végétaux et recherches sur lorigine des chromoplastides et le mode de formation des pigments xanthophylliens et carotiniens. Revue Générale de Botanique 31: 635-770.

Guilliermond A. 1921. Sur les microsomes et les formations lipoides de la cellule vegetale. Comptes rendus de l'Académie des Sciences 172: 1676-1678.

Haasis FW. 1944. Staining rubber in ground or milled plant tissues. Industrial \& Engineering Chemistry Analytical Edition 16: 480-481.

Hartman TL. 1940. The use of Sudan Black B as a bacterial fat stain. Stain Technology 15: 23-28.

Horobin RW. 2002. Dis-, tris- and polyazo dyes. In: Horobin RW, Kiernan JA. (eds.) Conn's Biological Stains. Handbook of dyes, stains and fluorochromes for use in biology and medicine. Oxford, BIOS Scientific Publishers. p. 125-144.

Horobin RW, James NT. 1970. The staining of elastic fibers with Direct Blue 152. A general hypothesis for the staining of elastic fibers. Histochemie 22: 324-336.

Knight TG, Klieber A, Sedgley M. 2002. Structural basis of the rind disorder oleocellosis in Washington navel orange (Citrus sinensis L. Osbeck). Annals of Botany 90: 765-773.

Kroemer K. 1903. Wurzelhaut, hypodermis und endodermis der angiospermenwurzeln. Bibliotheca Botanica 12: 1-159.

Lansink AGW. 1968. Thin layer chromatography and histochemistry of Sudan Black B. Histochemie 16: 68-84.

Lillie RD. 1977. Hj Conn's Biological Stains: A handbook on the nature and uses of the dyes employed in the biological laboratory. 9th edn. Baltimore, The Williams \& Wilkins Company.

Lison L, Dagnelie J. 1935. Méthodes nouvelles de coloration de la myéline. Bulletin d'histologie Appliquee a la Physiologie et a la Pathologie et de Technique Microscopique 12: 85-91.

McDowell EM, Trump B. 1976. Histological fixatives for diagnostic light and electron microscopy. Archives of Pathology \& Laboratory Medicine 100: 405-414.

McGee PA, Furby JH. 1992. Formation and structure of mycorrhizas of seedlings of coachwood (Ceratopetalum apetalum). Australian Journal of Botany 40: 291-304.

Ngoma Z, Haumont S. 1974. La distribution des lipides dans l'os compact révélée par le noir Soudan B. Acta Histochemica 495: 220-227. 
O'Brien TP, McCully ME. 1981. The Study of Plant Structure Principles and Selected Methods. Melbourne, Termarcarphi Pty Ltd.

Oliveira JMS. 2015. Simultaneous dehydration and infiltration with (2-hydroxyethyl)-methacrylate (HEMA) for lipid preservation in plant tissues. Acta Botanica Brasilica 29: 207-212.

Pfüller U, Franz H, Preiss A. 1977. Sudan Black B: Chemical structure and histochemistry of the blue main components. Histochemistry 54: 237-250.

Romijn HJ, Uum JF, Breedijk I, Emmering J, Radu I, Pool CW. 1999. Double immunolabeling of neuropeptides in the human hypothalamus as analyzed by confocal laser scanning fluorescence microscopy. Journal of Histochemistry \& Cytochemistry 47: 229-235.
Rosenberg M, Bartl P, Lesko J. 1960. Water-soluble methacrylate as an embedding medium for the preparation of ultrathin sections. Journal of Ultrastructure Research 4: 298-303.

Smart MG, Aist JR, Israel HW. 1986. Structure and function of wall appositions. 1. General histochemistry of papillae in barley coleoptiles attacked by Erysiphe graminis f. sp. hordei. Canadian Journal of Botany 64: 793-801.

Ventrella MC, Almeida AL, Nery LA, Coelho VPDM. 2013. Métodos histoquímicos aplicados às sementes. Viçosa, Universidade Federal de Viçosa. 